\title{
Interculturalidad y Cooperativismo
}

\author{
Enrique Gadea
}

Universidad de Deusto

\section{El cooperativismo como movimiento mundial}

Para valorar la amplitud del movimiento cooperativo es significativo aludir a las estadísticas globales de la Alianza Cooperativa Internacional, que tiene como miembros 175 organismos nacionales y regionales, de 65 países pertenecientes a todos los continentes, organismos que representan a 335 millones de socios individuales. Es más, si tomamos en consideración los sistemas o ramas del cooperativismo que no pertenecen a la $\mathrm{ACl}$, incluidos los de la China, el movimiento mundial abarca más de 500 millones de personas, lo que significa que es el movimiento socioeconómico más grande del mundo (A.F. LAIDLAW: Las cooperativas en el año 2000, Fondo Editorial Cooperativo, Bogotá, 1981, p. 19).

Se encuentran cooperativas en todos los sectores y en todos los países, incluso en aquellos que mantienen culturas más diferenciadas. $Y$ es que, es indudable que existe algo de universal en las cooperativas y en los cooperativistas: debajo de la actividad económica siempre subyace una forma de hacer para contribuir a crear un mundo más justo, diferente y mejor.

Logros cooperativos no faltan; en este sentido, cabe destacar desde las cajas cooperativas agrícolas de Francia, que ocupan el segundo lugar en el sistema bancario y de crédito del mundo; hasta las cooperativas agrícolas de los países escandinavos, que han obtenido amplias cuotas de mercado, que alcanza en algunos productos hasta el noventa por ciento; y ello sin olvidar que las cooperativas de Mondragón figuran entre los mayores fabricantes de refrigeradores y aparatos domésticos o que las cooperativas de distribución de fluido eléctrico han tenido a su cargo la iluminación del campo en Esta- 
dos Unidos (sobre el tema, ampliamente, A.F. LAIDLAW: ob. cit., p. 19). Cuestión distinta es si el movimiento cooperativo internacional se ha esforzado suficientemente o si ha conseguido mostrar hasta qué punto las cooperativas constituyen instrumentos adecuados para hacer frente a los problemas del mundo actual. Repárese en que el Cooperativismo y su manifestación práctica: la formula cooperativa, puede servir tanto para desarrollar la actividad empresarial de los pobres (en este sentido, como ha señalado el profesor J. Divar, en Globalización y Democracia, Dykinson, Madrid, 2005, p. 16, las cooperativas constituyen la aportación organizada empresarial más eficiente que puede hacerse al Ilamado Tercer Mundo, si queremos superar la humillante caridad), como para suavizar los actuales valores materialistas e insolidarios de los países desarrollados. En este ámbito, el ideario cooperativo recoge los principios y caracteres de la democracia económica, que puede conducir a la corrección del capitalismo (ampliamente, J. DIVAR: ob. cit., pp. 76 y ss.).

\section{Los valores y principios cooperativos como doctrina universal}

Los doctrina cooperativa de Rochdale reinterpretada por la $\mathrm{ACl}$ para adaptarla a los tiempos constituye una doctrina universal, que une a millones de personas de diferentes culturas y países que ven necesaria la unión de los débiles para lograr mayor fuerza; que valoran la asociación para afrontar problemas comunes; que pretenden la justa participación en las ganancias y en las pérdidas; que se decantan por la primacía del hombre sobre el dinero; o que persiguen la gestión democrática de la empresa frente a la simple opción capitalista.

Esta doctrina individualizadora del movimiento se recoge mediante la enunciación de los llamados principios cooperativos, formulados en París en 1937, y reformulados en Viena en 1966 y en Manchester en 1995. Ciñéndonos a lo más reciente, señalaremos que los principios acordados por la $\mathrm{ACl}$ en 1966 se redactaron en términos tan generales que se podría clasificar como cooperativas a los colectivos socialistas, así como a pseudocooperativas controladas por el Estado y a empresas de interés general. Después del colapso de las economías de planificación centralizada de orientación socialista y del fracaso evidente de las cooperativas controladas por el Estado, la opinión generalizada coincidía en la necesidad de replantearse los valores básicos cooperativos y de revisar sus principios, no con el ánimo de cambiarlos 
sino de expresarlos con mayor claridad (H.H. MünKNER: «Valores básicos cooperativos para llenar un vacío conceptual con especial atención a Africa», Anuario de Estudios Cooperativos de la Universidad de Deusto, 1995, p. 302). De ahí que el principal logro del Congreso de Manchester celebrado en 1995 es, sin duda, su Declaración sobre la Identidad Cooperativa. En la Declaración, que se explica con claridad la esencia del movimiento cooperativo y el papel del Cooperativismo de cara al nuevo milenio, pueden distinguirse tres partes: una definición de Cooperativa, una lista de los valores clave del Cooperativismo y una redefinición de los principios cooperativos para ajustarlos a las nuevas realidades sociales:

\section{1. ${ }^{a}$ Definición de Cooperativa}

La Declaración define la cooperativa como «una asociación autónoma de personas que se han unido de forma voluntaria para satisfacer sus necesidades económicas, sociales y culturales en común mediante una empresa de propiedad conjunta y de gestión democrática».

Esta definición no es una definición jurídica en sentido estricto, pretende ser una declaración de mínimos, útil para la redacción de las legislaciones, la educación de los socios y la preparación de libros de texto.

\section{2. ${ }^{a}$ Valores Cooperativos}

Sobre los valores cooperativos, la Declaración de la Alianza de 1995 dice que las cooperativas están basadas en los valores de la autoayuda, la autorresponsabilidad, la democracia, la igualdad, la equidad y la solidaridad. Además, destaca que, siguiendo la tradición de sus fundadores, los socios cooperativos — sin descartar que puedan encontrarse en otro tipo de organizaciones - hacen suyos los valores éticos de la honestidad, la transparencia, la responsabilidad y la vocación sociales.

El movimiento cooperativo tiene una historia intelectual larga y distinguida. En el curso de la misma ha habido grandes aportaciones, de diferentes teóricos de varias partes del mundo. Por eso, conseguir 
un consenso sobre los valores cooperativos esenciales ha sido una tarea compleja. En 1990 y 1992, bajo la dirección del Sr. Sven Böök, de Suecia, miembros de la $\mathrm{ACl}$ e investigadores independientes se dedicaron a una extensa discusión sobre la naturaleza de los valores cooperativos. Los resultados de ese estudio están recogidos en el libro "Los Valores Cooperativos en un mundo en cambio», escrito por Böök y publicado por la ACl. Ese libro, junto con «Principios Cooperativos: Hoy y mañana», escrito por W.P. Watkins, constituyen los pilares sobre los que se asentó la Declaración sobre Identidad Cooperativa.

Los valores específicos de las sociedades cooperativas son los recogidos en la primera frase sobre los valores de la Declaración de Manchester: "Las cooperativas están basadas en los valores de la autoayuda, la autorresponsabilidad, la democracia, la igualdad, la equidad y la solidaridad». Para explicar cada uno de ellos, en el referido Informe de la $\mathrm{ACl}$ se apunta lo siguiente:

La «autoayuda» se basa en la creencia de que todo el mundo puede y debería esforzarse por controlar su propio destino. Los cooperativistas creen, sin embargo, que el desarrollo individual pleno solamente puede producirse en asociación con los demás. Como individuo, uno está limitado en lo que puede intentar hacer, y en lo que puede conseguir. A través de la acción conjunta y de la responsabilidad mutua, se puede conseguir más, especialmente aumentando la influencia colectiva de uno en el mercado y ante los gobiernos.

Los individuos también se desarrollan como personas mediante la acción cooperativa debido a las habilidades que adquieren al facilitar el crecimiento de su cooperativa, al conocimiento que consiguen de sus compañeros, a las nuevas percepciones que alcanzan sobre la sociedad más amplia de la que forman parte. En este sentido, las cooperativas son instituciones que fomentan la educación y desarrollo continuos de todos los implicados.

La «autorresponsabilidad» significa que los socios asumen la responsabilidad de la fundación y de la vida de la cooperativa. Además, son los responsables de promover su cooperativa entre sus familias, amigos y conocidos. Este valor cooperativo también significa que los socios son responsables de asegurarse que su cooperativa permanece independiente de otras organizaciones públicas o privadas. 
Las cooperativas están basadas en la igualdad, constituyendo su unidad básica el socio. Esta fundamentación en la persona humana es una de las principales características que distingue a una cooperativa de las empresas orientadas principalmente en beneficio del capital. Los socios tienen el derecho de participación, el derecho de ser informados, el derecho de ser escuchados y el derecho de estar involucrados en la toma de decisiones. Los socios deberían estar asociados de la forma más igualitaria posible, lo que es a veces una tarea difícil en las grandes cooperativas o en federaciones de cooperativas. De hecho, la preocupación para conseguir y mantener la igualdad es un reto continuo para todas las cooperativas. En última instancia, se trata tanto de una forma de intentar hacer los negocios como de una pura y simple declaración de principios.

También conseguir la equidad dentro de la cooperativa es un reto continuo. La equidad se refiere a cómo se trata a los socios en una cooperativa. Deben ser tratados equitativamente en cuanto a la forma de recompensar su participación en la cooperativa, normalmente mediante retornos, asignaciones a reservas de capital en su nombre, o reducciones en precios. La equidad es importante para las cooperativas, porque es la forma en la que intentan distribuir ganancias o riqueza en base a la contribución y no a la especulación.

La «solidaridad» asegura en las cooperativas que la acción derivada de esta organización no es simplemente una forma disfrazada de interés personal ilimitado. Una cooperativa es más que una asociación de socios; es también una colectividad. Los socios tienen la responsabilidad de asegurar que todos ellos son tratados de la forma más justa posible.

Además, la «solidaridad» significa aspiración a crear un movimiento cooperativo unido, local, nacional, regional e internacionalmente. Los cooperativistas aceptan que hay un punto común entre todas las cooperativas sin importar sus diferentes fines y sus diferentes contextos.

Finalmente, hay que resaltar que la solidaridad es la misma causa y consecuencia de la autoayuda y la ayuda mutua, dos de los conceptos fundamentales de la filosofía cooperativa; conceptos que constituyen la base para diferenciar las cooperativas de otras formas de organización económica. 


\section{3. ${ }^{\text {Principios Cooperativos }}$}

Los principios cooperativos son definidos por la Declaración como pautas mediante las cuales las cooperativas ponen en práctica sus valores. Es indudable que son mandamientos que deben ser seguidos por las cooperativas, aunque, como acertadamente destaca el Informe de la Alianza, no es suficiente preguntar si una cooperativa está siguiendo al pie de la letra un principio, es igualmente importante saber si está siguiendo su espíritu. Si la visión que proporciona cada principio, individual y colectivamente, está arraigada en las actividades diarias de la cooperativa. Además, no pueden considerarse independientes: los principios están unidos sutilmente. Cuando se pasa uno por alto, todos se resienten. No hay que evaluar las cooperativas exclusivamente sobre la base de un principio dado, más bien, deben ser evaluadas sobre la base de cómo se adhieren a los principios en su totalidad.

Hay siete principios listados en la Declaración de 1995: Adhesión Voluntaria y Abierta; Gestión Democrática por parte de los socios; Participación Económica por parte de los socios, Autonomía e Independencia; Educación, Formación e Información; Cooperación entre Cooperativas; e Interés por la Comunidad. Los tres primeros principios se dirigen a la dinámica interna típica de cualquier cooperativa. Los cuatros últimos se dirigen tanto al funcionamiento interno como a las relaciones externas de las cooperativas.

En la Declaración de 1995 los principios han sido formulados de la forma siguiente:

1. Adhesión Voluntaria y Abierta: «Las cooperativas son organizaciones voluntarias, abiertas a todas las personas capaces de utilizar sus servicios y dispuestas a aceptar las responsabilidades de ser socio, sin discriminación social, política, religiosa, racial o de sexo».

2. 'Gestión Democrática por parte de los socios: «Las cooperativas son organizaciones gestionadas democráticamente por los socios, los cuales participan activamente en la fijación de sus políticas y en la toma de decisiones. Los hombres y las mujeres elegidos para representar y gestionar las cooperativas son responsables ante los socios. En las cooperativas de primer grado, los socios tienen iguales derechos de voto (un socio, 
un voto) y las cooperativas de otros grados están también organizadas de forma democrática».

3. Participación Económica de los socios: «Los socios contribuyen equitativamente al capital de sus cooperativas y lo gestionan de forma democrática. Por lo menos parte de ese capital debe ser propiedad común de la cooperativa. Normalmente, los socios reciben una compensación, si la hay, limitada sobre el capital entregado para adquirir la condición de socio. Los socios asignan los excedentes para todos o algunos de los siguientes fines: el desarrollo de su cooperativa, posiblemente mediante el establecimiento de reservas, parte de las cuales por lo menos serían indivisibles; el beneficio de los socios en proporción a sus operaciones con la cooperativa; y el apoyo de otras actividades aprobadas por los socios».

4. Autonomía e Independencia: «Las cooperativas son organizaciones autónomas de autoayuda, gestionadas por sus socios. Si firman acuerdos con otras organizaciones, incluidos los gobiernos, o si consiguen capital de fuentes externas, lo hacen en términos que aseguren el control democrático por parte de sus socios y mantengan su autonomía cooperativa».

5. Educación, Formación e Información: «Las cooperativas proporcionan educación y formación a los socios, a los representantes elegidos, a los directivos y a los empleados para que puedan contribuir de forma eficaz al desarrollo de sus cooperativas. Informan al gran público, especialmente a los jóvenes y a los lideres de opinión, de la naturaleza y beneficios de la cooperación».

6. Cooperación entre cooperativas: «Las cooperativas sirven a sus socios lo más eficazmente posible y fortalecen el movimiento cooperativo trabajando conjuntamente mediante estructuras locales, nacionales, regionales, e internacionales».

7. Interés por la Comunidad: «Las cooperativas trabajan para conseguir el desarrollo sostenible de sus comunidades mediante políticas aprobadas por sus socios».

En esta declaración destaca la incorporación de dos nuevos principios, el cuarto, que no se recogió explícitamente en la formulación de 1996 para evitar la salida de la ACl de los países de regímenes comunistas, dado que limitaban la autonomía e independencia de sus cooperativas, y el séptimo, dado que en 1966, al enunciar el sexto 
principio de cooperación entre cooperativas, se señaló como objetivo «servir mejor a los intereses de sus miembros y de la comunidad»; en cambio, en 1995, se concede mayor importancia a este objetivo, atribuyendo a la «preocupación por la comunidad» el carácter de principio.

\section{La educación cooperativa}

El movimiento cooperativo ha tenido y debe mantener un compromiso claro con la educación. Tal como señala la Declaración de 1995 —en el quinto principio-, los fondos cooperativos destinados a este fin deben dedicarse a la educación — dirigida a la comprensión de la complejidad y riqueza del pensamiento y acción cooperativosy a la formación — dirigida a la capacitación profesional- de todos lo que están implicados en las cooperativas, no sólo de los socios, y a la información al gran público —especialmente a los jóvenes y a los lideres de opinión - de la naturaleza y beneficios de la cooperación. Es un hecho generalmente aceptado que en nuestros días se ha descuidado la actividad educativa en las propias cooperativas. En la práctica se corre el riesgo de descuidar la actividad cooperativa, si el consejo de administración no le presta a este asunto la atención que merece y no asume la responsabilidad que le incumbe al respecto. Realizar especial hincapié en esta última actividad tiene gran importancia para el desarrollo futuro del Cooperativismo, ya que nadie aprecia ni apoya lo que no entiende.

En esa dirección apuntar que también es fundamental dar a conocer el ideario cooperativo entre los jóvenes y que para desarrollar esa actividad debe ocupar un importante papel la Universidad.

Ya ha sido planteada la cuestión de cómo encajar los estudios sobre Cooperativismo en los planes de estudios de grado y de postgrado:

En los estudios de grado ha surgido la duda de si es mejor explicar los contenidos en las asignaturas clásicas (mercantil, laboral, fiscal...) o crear una asignatura especifica. La solución no es fácil: la práctica demuestra que dentro de los amplios temarios de las asignaturas troncales, la explicación de los contenidos relativos al ámbito cooperativo ocupa un papel marginal. Parece, por tanto, mejor opción la introducción de una asignatura, aunque sea optativa, que aborde el temario 
cooperativo. Sin embargo, esta opción plantea el problema de la diversidad de contenidos. Ello exige que la asignatura sea impartida, no por un solo profesor sino por un grupo de profesores especialistas en las diferentes materias. Solo así se garantiza el rigor y la imagen universitaria adecuada.

En los estudios de postgrado, además de la existencia de sólidos cursos de Doctorado sobre Instituciones cooperativas, se considera necesaria la creación de cursos de especialización dirigidos a titulados en general y a dirigentes y socios de cooperativas.

Por tanto, cierto es que las líneas de actuación están marcadas y también lo es que ha habido ensayos y logros reseñables en este ámbito, aunque no lo es menos que, en la actualidad, y probablemente favorecido, entre otras razones, por el referido descuido de la faceta educativa por las propias cooperativas, la contribución de la Universidad a la Educación Cooperativa debería ser revitalizada a través de medidas concretas y, muy especialmente, mediante la promoción del Cooperativismo entre los estudiantes (vía conferencias, jornadas, publicaciones...) y con la firma de convenios entre Universidades y las propias cooperativas o sus Federaciones, con el objeto de facilitar el acceso de sus directivos y socios a los cursos de especialización cooperativa. Y es que, como señalábamos anteriormente, no se apoya lo que no se entiende, por mucho que en el Cooperativismo pueda encontrarse la verdadera democracia económica y que sobre la base de la caracterización universal cooperativista pueda constituirse una sociedad mejor. 